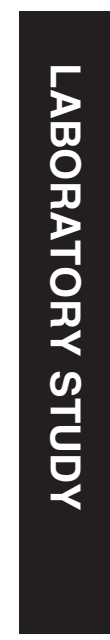

\section{Influence of cataract maturity on aqueous humor lipid peroxidation markers and antioxidant enzymes}

\begin{abstract}
Purpose The impact of cataract maturity on the aqueous humor (AH) oxidant/antioxidant balance is largely controversial. This study was aimed at assessing the relationships between cataract maturity and $\mathrm{AH}$ lipid peroxidation markers and enzymatic antioxidants. Patients and methods The concentrations of conjugated dienes (CD), lipofuscin-like fluorescent end-products (LLF), soluble proteins, as well as the activities of superoxide dismutase (SOD) and catalase (CAT) were measured in AH samples from nondiabetic patients with either immature $(n=15)$ or mature $(n=15)$ cataract.

Results In the overall AH sample, the mean values of CD, LLF, SOD, and CAT were $0.160 \pm 0.024\left(\mathrm{OD}_{234}\right), 166 \pm 27 \mathrm{RFU}$, $24.5 \pm 7.1 \mathrm{U} / \mathrm{ml}$, and $31.9 \pm 3.9 \mathrm{pmol} / \mathrm{ml}$, respectively. CD was positively correlated with SOD $(r=0.647 ; P<0.001)$, CAT $(r=-0.394 ; P=0.031)$, and LLF $(r=-0.399$; $P=0.029)$. The LLF was negatively correlated with SOD $(r=-0.461 ; P=0.010)$. In samples adjusted for confounding factors, differences between immature and mature cataract groups regarding SOD, CD, LLF, and total proteins were significant $(P<0.05$; for all variables). The multiple logistic regression analysis identified $L L F(O R=4.08 ; P=0.038)$ and $\operatorname{SOD}(\mathrm{OR}=4.99 ; P=0.031)$ as independent predictors of cataract maturity. Conclusions These results suggest that $\mathrm{AH}$ lipid peroxidation markers and antioxidants may significantly depend on the cataract maturity stage.
\end{abstract}

Eye (2014) 28, 72-77; doi:10.1038/eye.2013.207; published online 4 October 2013
DJ Miric ${ }^{1}$, BM Kisic ${ }^{1}$, LD Zoric ${ }^{2}$, BM Miric $^{3}$, M Mirkovic ${ }^{2}$ and R Mitic ${ }^{4}$
Keywords: aqueous humor; cataract maturity; oxidative stress; conjugated dienes; lipofuscin-like fluorophores; superoxide dismutase

\section{Introduction}

Biochemical evaluation of various eye diseases often includes analyses of aqueous humor (AH), an ocular fluid continuously formed by ultrafiltration of blood plasma and actively secreted by ciliary body. Although it has numerous supportive roles, AH may also be the source of powerful oxidants, such as hydrogen peroxide $\left(\mathrm{H}_{2} \mathrm{O}_{2}\right)$ and singlet oxygen, generated during photooxidation of endogenous UV filters, including ascorbic acid. It is now well established that excess levels of ocular oxidants can cause damage to the lens and other tissues, which are implicated in normal ageing process and in pathogenesis of several eye diseases, such as pseudoexfoliation syndrome, diabetic retinopathy, glaucoma, and senile cataract (SC) ${ }^{1-7}$ The toxicity of oxidants depends on their ability to induce cross-linking, aggregation, fragmentation, and insolubilization of structural proteins, inactivation of enzymes, and lipid peroxidation (LPO) of the membrane-bound polyunsaturated fatty acids (PUFA), leading to impaired cell function, apoptosis, and necrosis. ${ }^{1,2}$

Unlike ocular tissues, AH contains only small quantities of proteins and antioxidant enzymes, and its antioxidant defense thus relies on unusually high levels of low-molecular weight antioxidants, mostly ascorbic acid, present at the level of $\sim 1 \mathrm{mM}$, even in SC. ${ }^{7}$ There is, 
however, no reliable data about peroxide levels in $\mathrm{AH}$ under either physiological or pathological conditions, presumably because such amounts of ascorbic acid strongly interfere with most biochemical methods commonly used for the estimation of $\mathrm{H}_{2} \mathrm{O}_{2} .{ }^{8}$ An alternative method is to measure different LPO adducts that, due to essentially dynamic nature of the LPO process, may offer a temporal insight into oxidant/ antioxidant balance. Conjugated dienes (CD) are organic peroxides formed in vivo, soon after initiation of LPO, as unstable intermediary products that subsequently decompose to a number of reactive lipid-derived aldehydes. ${ }^{9}$ In the following nonenzymatic reactions, these carbonyl compounds may react with macromolecules, giving rise to chemically diverse fluorescent-conjugated Schiff's bases, known as lipofuscin-like fluorophores (LLF). ${ }^{10}$ Because of their chemical stability, these LLF are considered to be the reliable marker of chronic oxidative stress in vivo. ${ }^{11}$

Concentration of oxidants is in $\mathrm{AH}$ regulated by a variety of low-molecular as well as enzymatic antioxidants, including superoxide dismutase (SOD), catalase (CAT), and glutathione peroxidases (GPx). 4,5,7,12 Although $\mathrm{AH}$ is in direct contact with lens surface, little is known about changes in LPO markers and antioxidants caused by the progression of SC.

Considering that oxidative stress markers in SC are often compared with other eye diseases, and that $\mathrm{AH}$ pathway may be used for targeting ocular antioxidant defense, we aimed this study at assessing the impact of SC maturity on AH LPO markers and antioxidants.

\section{Materials and methods}

\section{Patients}

A total of 30 patients (30 eyes) with idiopathic SC (14 women and 16 men) were included in the study upon obtaining written informed consent. All patients underwent planned surgical removal of cataract followed by an intraocular implantation of artificial lens. The clinical type and maturity of cataract were determined by routine ophthalmic examination and confirmed at the time of cataract surgery. The immature cataract group $(n=15)$ consisted of 5 nuclear, 2 posterior subcapsular, 1 cortical, and 7 mixed opacities; the remaining cases $(n=15)$ included white mature cataract. Patients with eye diseases other than SC, hypermature SC, as well as those with chronic metabolic, inflammatory, or malignant diseases were not included in this study. The study was conducted in accordance with tenets of the Declaration of Helsinki and approved by the Ethical Committee of Medical Faculty at Kosovska Mitrovica.

\section{Sample collection}

At the beginning of surgical procedure, about $0.15 \mathrm{ml}$ of $\mathrm{AH}$ was aspirated from the anterior eye chamber with a 25-gauge needle connected to a tuberculin syringe and placed into Eppendorf microtube (Sigma-Aldrich Co., St Louis, MO, USA). Samples were immediately delivered to the laboratory packed on dry ice and kept at $-20^{\circ} \mathrm{C}$ for no longer than 14 days.

\section{Biochemical methods}

Determination of SOD activity SOD activity was determined by using the method of inhibition of adrenaline autoxidation, ${ }^{13}$ with adrenaline bitartarate $(7 \mathrm{mmol} / \mathrm{l})$ as a substrate. The increase in absorbance of adrenochrome was monitored for $5 \mathrm{~min}$ at $\lambda=480 \mathrm{~nm}$ on an UV/VIS spectrophotometer fitted with constant temperature cell housing (Safas-2, SAFAS, Monaco). The results were expressed as units of SOD activity per milliliter of AH. One unit of SOD activity was defined as the quantity of enzyme that inhibits autoxidation of $5 \mathrm{mmol}$ of adrenaline by $50 \%$.

\section{Measurement of CAT activity CAT activity was} determined by the UV kinetic method. ${ }^{14}$ The reaction was started by adding $200 \mu \mathrm{l}$ of $38 \mathrm{mmol} / 1 \mathrm{H}_{2} \mathrm{O}_{2}$ (freshly prepared in phosphate buffer), and the absorbance was monitored for $5 \mathrm{~min}$ at $\lambda=240 \mathrm{~nm}$. CAT activity was calculated using the molar absorption coefficient of $\varepsilon=4.36 \times \mathrm{L} \times \mathrm{cm} \times \mathrm{M}^{-1}$. The results were corrected for spontaneous breakdown of $\mathrm{H}_{2} \mathrm{O}_{2}$, and expressed in pmol of $\mathrm{H}_{2} \mathrm{O}_{2}$ per milliliter of $\mathrm{AH}$.

\section{Measurement of baseline CD concentration Baseline CD} concentration was determined by the method described by Chajes et al. ${ }^{9}$ Specifically, AH $(50 \mu \mathrm{l})$ was mixed with $0.5 \mathrm{ml}$ of water, and lipids were extracted following addition of $1.5 \mathrm{ml}$ of chloroform-methanol mixture $(2: 1 ; \mathrm{v} / \mathrm{v})$ supplemented with butylated hydroxytoluene $(5 \mathrm{mg} / 100 \mathrm{ml})$, vortex mixed and separated by centrifuging for $5 \mathrm{~min}$ at $2000 \times g\left(4^{\circ} \mathrm{C}\right)$. The lower chloroform layer was removed and evaporated under a stream of nitrogen until dry. The lipid residue was redissolved in $1 \mathrm{ml}$ of cyclohexane and the absorbance was measured at $\lambda=234 \mathrm{~nm}$. The results are presented as relative units of optical density $\left(\mathrm{OD}_{234}\right)$.

Measurement of LLF concentration Concentration of LLF was measured by Shimasaki's method. ${ }^{15}$ In brief, $50 \mu \mathrm{l}$ of $\mathrm{AH}$ was extracted in $1 \mathrm{ml}$ ethanol/ether $(3: 1, \mathrm{v} / \mathrm{v})$, mixed in vortex and centrifuged (10 min; $2000 \times g ; 4 \mathrm{C})$. Fluorescence of supernatant was measured at $360 / 430 \mathrm{~nm}$ (excitation/emission) in the fluorescent 
photometer equipped with a xenon lamp (Jenway 6285, Barloworld Scientific Ltd, Dunmow, UK). The results are presented as relative fluorescence units (RFU).

Protein concentration assay The total protein concentration was determined by Lowry's photometric method, with human albumin $(1 \mathrm{~g} / \mathrm{l})$ used for calibration. ${ }^{16}$

\section{Statistical methods}

Statistical analyses were performed using STATISTICA software package, version 6.0 (Statsoft Inc, Tulsa, OK, USA). Data were presented as mean value \pm SD or frequencies $(n)$. Differences among groups were tested using one-way analysis of variance (ANOVA), Student's t-test, or chi-square test, as appropriate. Correlation analysis was accomplished by calculating Spearman's coefficient. The influence of confounding factors on biochemical variables was assessed by general regression models and presented as Pareto chart. The relationship between cataract maturity and standardized biochemical variables was assessed by multiple logistic regression analysis. The results were expressed as odds ratio (OR) and $95 \%$ confidence interval (CI). Statistical significance was set at $P<0.05$.

\section{Results}

Thirty AH samples were obtained from 30 patients (mean age $75.3 \pm 5.6$ years) with either immature $(n=15)$ or mature $(n=15)$ SC. According to medical files, seven patients with immature and nine with mature SC were treated for hypertension (chi-square $=0.134 ; P=0.714$ ), whereas eight patients with immature and five with mature SC were treated for chronic cardiomyopathy (chi-square $=0.543 ; P=0.461$ ).

Three groups were formed to examine the influence of age on studied variables: Group I ( $\leq 70$ years; $n=7$ ), Group II (71-80 years; $n=16$ ), and Group III ( $>80$ years; $n=7$ ). Mature cataract occurred more frequently in older groups (chi-square $=5.11 ; P=0.078$ ) and that trend was significant (chi-square $=4.57 ; P=0.033$ ). In comparison with the younger group, the LLF was higher, whereas SOD, and to some extent CD and proteins, were lower in older groups (Table 1). Relative contributions of age, gender, hypertension, and cardiomyopathy to aqueous CD, LLF, SOD and CAT are presented in Pareto chart (Figure 1).

After adjustment for confounding factors, the overall mean levels of CD were $0.160 \pm 0.024\left(\mathrm{OD}_{234}\right)$, and $166 \pm 27$ RFU for LLF. The mean overall activity of SOD was $24.5 \pm 7.1 \mathrm{U} / \mathrm{ml}$ and the mean CAT activity was $31.9 \pm 3.9 \mathrm{pmol} / \mathrm{ml}$. CD was correlated with CAT $(r=-0.394 ; P=0.031), \operatorname{LLF}(r=-0.399 ; P=0.029)$, and SOD $(r=0.647 ; P<0.001)$. The LLF was negatively correlated with SOD $(r=-0.461 ; P=0.010)$. AH proteins were correlated with SOD $(r=0.371 ; P=0.043)$, but not with CAT $(r=-0.117 ; P=0.538)$.

In comparison to immature SC, the SOD activity, and $\mathrm{CD}$ and soluble protein concentrations were lower in the mature SC group, whereas LLF concentration was higher (Table 2). The multiple logistic regression analysis was performed on standardized biochemical variables, using cataract maturity as a dependent variable. Our results showed (Table 3$)$ that elevated $\mathrm{LLF}(\mathrm{OR}=4.08 ; 95 \% \mathrm{CI}$ : $1.08-15.41 ; P=0.038)$ and decreased SOD $(\mathrm{OR}=4.99 ; 95 \% \mathrm{CI}$ : $1.16-21.59 ; P=0.031)$ were independent predictors of cataract maturity.

\section{Discussion}

This study showed that with the ageing process, cataract maturity may also have a significant impact on levels of $\mathrm{AH}$ oxidants and antioxidants. AH contains approximately $4 \mu \mathrm{g} / \mathrm{ml}$ of HDL lipoproteins whose PUFA can be subjected to LPO, but may include a broad spectrum of other molecules and LPO adducts originating from adjacent injured or apoptotic cells, resulting in LLF levels of about 130 RFU in aged noncataractous subjects. ${ }^{2,17}$ In the current study, almost all biochemical variables displayed age-related

Table 1 Age-related changes of aqueous humor variables in total study group $(n=30)$

\begin{tabular}{lcc}
\hline & $\begin{array}{c}\text { Group } I(\mathrm{n}=7) \\
(61-70 \text { years })\end{array}$ & $\begin{array}{c}\text { Group II }(\mathrm{n}=16) \\
(71-80 \text { years })\end{array}$ \\
\hline CD $\left(\mathrm{OD}_{234}\right)$ & $0.176 \pm 0.032$ & $0.153 \pm 0.039$ \\
$\mathrm{LLF}(\mathrm{RFU})$ & $146.7 \pm 29.5$ & $165.8 \pm 24.7$ \\
$\mathrm{SOD}(\mathrm{U} / \mathrm{ml})$ & $32.3 \pm 11.7$ & $23.1 \pm 10.6$ \\
$\mathrm{CAT}(\mathrm{pmol} / \mathrm{ml})$ & $28.1 \pm 8.0$ & $30.8 \pm 10.5$ \\
Proteins $(\mathrm{mg} / \mathrm{ml})$ & $1.72 \pm 0.26$ & $1.85 \pm 0.63$ \\
Immature/Mature SC $(n / \mathrm{n})$ & $6 / 1$ & $7 / 9$ \\
\hline
\end{tabular}

Data are given as mean values $\pm \mathrm{SD}$ or frequencies $(n)$

${ }^{\mathrm{a}} P<0.05$ vs Group I, after ANOVA.

${ }^{\mathrm{b}} \mathrm{P}<0.05$ for a trend, after chi-square test. 
a

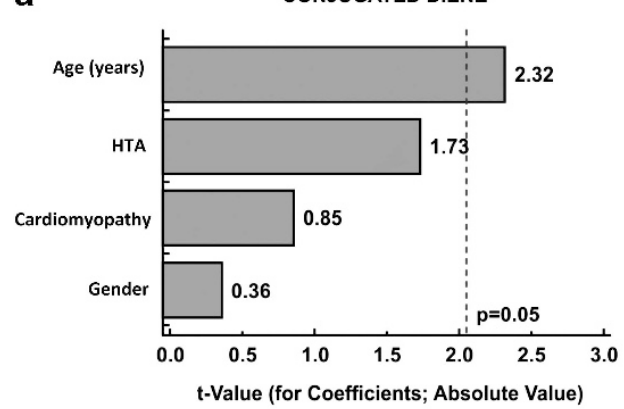

c

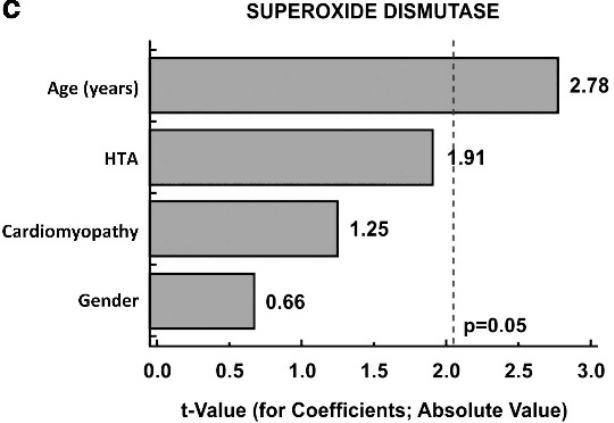

b

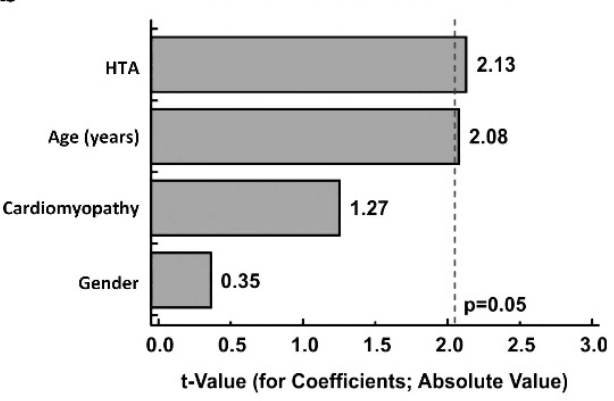

d

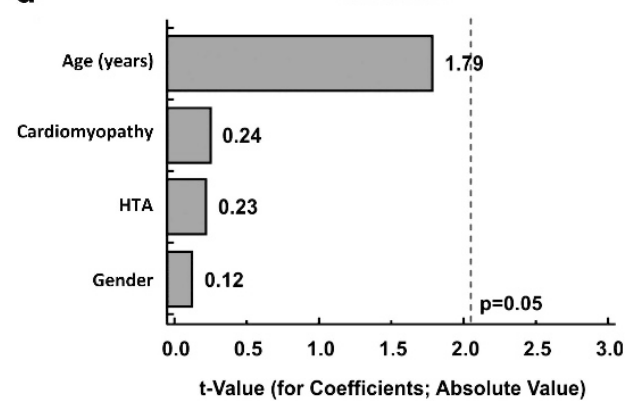

Figure 1 Pareto chart representing absolute $t$-values from multiple regression analysis for relative impact of age, gender (male), hypertension (HTA), and cardiomyopathy on (a) conjugated diene, (b) lipofuscin-like fluorophore, (c) superoxide dismutase, and (d) catalase in $\mathrm{AH}$ of eyes with senile cataract.

dependency (Figure 1) in such way that levels of LPO adducts were increased, whereas SOD and, to some extent, total proteins and CAT were decreased in elderly groups (Table 1).

Beyond ageing process, there could be multiple other factors influencing the $\mathrm{AH}$ oxidative stress markers. Hypertensive patients, for example, had higher LLF levels than normotensive ones (Figure 1b; Beta \pm SE: $0.412 \pm 0.193 ; t=2.13 ; P=0.043)$, which is in agreement to higher plasma LLF levels in hypertensive noncataract subjects. ${ }^{18}$ The maturation stage of SC also had a significant impact on most of the $\mathrm{AH}$ variables. Moreover, of the two studied oxidative stress markers, the aqueous LLF showed an independent relationship with cataract maturity (Table 3). On the other hand, the concentration of $\mathrm{CD}$, indicating an ongoing LPO, was quite oppositely higher in the immature SC group (Table 2), but the relationship with cataract maturity was weaker (Table 3).

One probable explanation is that these findings actually reflect the dynamic nature of the LPO process, in which the formation of CD through PUFA peroxidation often slows down at the rate at which LLF are formed. ${ }^{19}$ Given that CD represent parent molecules of lipid-derived aldehydes and LLF, the inverse relationship between these LPO markers observed in the current study $(r=-0.399$; $P=0.029)$ could have been expected, suggesting more advanced LPO process in progressed disease.
Table 2 Effect of cataract maturity on aqueous humor variables

\begin{tabular}{lccr}
\hline & $\begin{array}{c}\text { Immature } \\
\text { cataract } \\
(\mathrm{n}=15)\end{array}$ & $\begin{array}{l}\text { Mature } \\
\text { cataract } \\
(\mathrm{n}=15)\end{array}$ & P-value \\
\hline $\mathrm{CD}\left(\mathrm{OD}_{234}\right)$ & $0.184 \pm 0.032$ & $0.157 \pm 0.030$ & 0.024 \\
$\mathrm{LLF}(\mathrm{RFU})$ & $148.3 \pm 24.9$ & $183.4 \pm 16.4$ & $<0.001$ \\
$\mathrm{SOD}(\mathrm{U} / \mathrm{ml})$ & $32.1 \pm 9.9$ & $21.7 \pm 7.1$ & 0.003 \\
$\mathrm{CAT}(\mathrm{pmol} / \mathrm{ml})$ & $31.0 \pm 9.7$ & $32.8 \pm 10.7$ & 0.622 \\
Proteins $(\mathrm{mg} / \mathrm{ml})$ & $2.01 \pm 0.52$ & $1.49 \pm 0.56$ & 0.014 \\
\hline
\end{tabular}

Data are given as mean values $\pm \mathrm{SD} ; P$-value after Student's $t$-test for independent samples.

Table 3 Logistic regression analysis for the impact of senile cataract maturity on standardized values of $\mathrm{AH}$ oxidative stress markers and antioxidants

\begin{tabular}{lllc}
\hline & \multicolumn{1}{c}{ OR } & \multicolumn{1}{c}{$95 \% \mathrm{CI}$} & $\mathrm{P}$ \\
\hline $\mathrm{CD}\left(\mathrm{OD}_{234}\right)$ & 3.023 & $0.802-11.403$ & 0.102 \\
$\mathrm{LLF}(\mathrm{RFU})$ & 4.077 & $1.078-15.414$ & 0.038 \\
$\mathrm{SOD}(\mathrm{U} / \mathrm{ml})$ & 4.995 & $1.155-21.598$ & 0.031 \\
$\mathrm{CAT}(\mathrm{pmol} / \mathrm{ml})$ & 0.887 & $0.178-4.386$ & 0.882 \\
\hline
\end{tabular}

AH normally contains just $0.03-0.50 \mathrm{mg} / \mathrm{ml}$ of soluble proteins filtrated from blood plasma through fenestrated capillaries of the ciliary body. ${ }^{20}$ In SC, these levels can be much higher and often exceed $1 \mathrm{mg} / \mathrm{ml}^{5}$ partly due to lens morphological changes, increased synthesis and diffusion of proteins through distended capsule into $\mathrm{AH}^{21}$ In progressed SC, the concentration of $\mathrm{AH}$ 
proteins may decrease (Table 2) as a result of decreased synthesis, and extensive oxidative modifications and insolubilization.

We noted that concentration of $\mathrm{AH}$ proteins was positively correlated with SOD activity $(r=0.371$; $P=0.043$ ), pointing to lenticular origin of the enzyme. The SOD is generally well expressed in ocular tissues, especially in those with intensive aerobic metabolism, but in normal $\mathrm{AH}$ its activity is only about $2.7 \mathrm{U} / \mathrm{ml}^{22}$ However, oxidants can strongly enhance the transcriptional activity of the lens SOD genes, ${ }^{23}$ probably contributing to average SOD activity of $24.5 \pm 7.1 \mathrm{U} / \mathrm{ml}$ in SC, as seen in this and some previous studies. ${ }^{4,7}$ The SOD activity was decreasing with age (Table 1; Figure 1c) and, although this was in contradiction with the results by Sawada et $a l_{1}^{5}$ it is in line with the evidence of decreased SOD in cataractous lens epithelial cells and trabecular meshwork of elderly. ${ }^{24,25}$

Enzymatic conversion of superoxide anion radicals to less reactive $\mathrm{H}_{2} \mathrm{O}_{2}$ by SOD is an important step that prevents oxidative damage. Paradoxically, however, an upregulated SOD can also be the source of oxidants. Under conditions where its activity exceeds the capacity of $\mathrm{H}_{2} \mathrm{O}_{2}$-degrading pathways, the accumulated $\mathrm{H}_{2} \mathrm{O}_{2}$ may induce inactivation of SOD causing partial release of copper from enzyme's active center, accompanied by formation of hydroxyl radicals. ${ }^{25-27}$ The inactivation of SOD can be more extensive in advanced SC, ${ }^{28}$ which probably explains the independent association between maturity of SC and decreased aqueous SOD activity (OR $=4.99 ; 95 \% \mathrm{CI}: 1.16-21.60 ; P=0.031)$ in the current study.

Ocular tissues can usually degrade considerable amounts of peroxides, mainly through increased activity of CAT, GPx, and glutathione S-transferases. For example, lens epithelial cells conditioned to survive lethal concentrations of $\mathrm{H}_{2} \mathrm{O}_{2}$ or tert-butyl hydroperoxide may express up to 115 times and 70 times higher CAT activity than untreated controls. ${ }^{12}$ However, the role of CAT in ocular antioxidant protection is not fully understood, partly because of overlapping substrate specificity with cellular GPx-1. The other reason is that in SC the antioxidant genes can be markedly downregulated, ${ }^{29}$ and the progression of SC has already been associated with decreased GPx activity, both at local and systemic level. ${ }^{2,3}$

Furthermore, lenses of acatalasemic mice were demonstrated to be almost as efficient in degrading the $\mathrm{H}_{2} \mathrm{O}_{2}$ ex vivo as those of the wild type, ${ }^{30}$ indicating that CAT itself may not be of critical importance for prevention of lens oxidative damage. In the current study, the average CAT activity in $\mathrm{AH}$ was $32 \mathrm{pmol} / \mathrm{ml}$, and was unrelated to oxidative stress status and, as in a previous study, ${ }^{5}$ unaffected by cataract maturity.
Although earlier studies reported up to $600 \mu \mathrm{M}$, it was recently suggested that the concentration of $\mathrm{H}_{2} \mathrm{O}_{2}$ probably does not exceed $25 \mu \mathrm{M}$, even in SC. ${ }^{1,8}$ Besides, organic peroxides can be more toxic to ocular tissues than $\mathrm{H}_{2} \mathrm{O}_{2}$, 2,31 and under such conditions, relative contribution of GPx to oxidant homeostasis may be greater than that of CAT because of its lower $K_{m}$ for $\mathrm{H}_{2} \mathrm{O}_{2}$ and ability to reduce both inorganic and organic peroxides.

AH oxidative stress markers and antioxidants are believed to mirror the intrinsic oxidant/antioxidant balance of the surrounding eye tissues. Our present study examined the impact of cataract maturity on several AH oxidative stress markers and antioxidants. According to our results, the maturity of SC was associated with significant imbalances between $\mathrm{AH}$ oxidants and antioxidants in terms of decreased SOD, total proteins, and CD, as well as increased LLF, whereas CAT activity remained unchanged. Although this study is limited by small sample size, the presented results suggest that most of the AH oxidative stress markers can be associated with maturation stage of SC. Therefore, the maturity of SC should be taken into account in biochemical studies of ocular oxidative stress.

\section{Summary}

What was known before

- Senile cataract can modify aqueous humor (AH) composition.

- There are equivocal results about the impact of cataract maturity on $\mathrm{AH}$ oxidative stress markers and antioxidants.

- Lipid peroxidation markers, conjugated dienes (CD) and lipofuscin-like fluorophores (LLF), are rarely measured in $\mathrm{AH}$. These markers seem to be reliable indicators of acute and chronic oxidative stress.

What this study adds

- The maturity of cataract was associated with significant changes in AH lipid peroxidation markers and antioxidants.

- Levels of SOD, total proteins, and CD were decreased, whereas LLF concentration was increased in mature cataract.

- In a logistic regression analysis the fall of SOD activity and elevation of LLF concentration were independently associated with cataract maturity.

- CAT activity was not dependent on maturation stage of cataract.

\section{Conflict of interest}

The authors declare no conflict of interest.

\section{Acknowledgements}

This work was partly supported by Ministry of Science and Technology of the Republic of Serbia, grant no. 145112. 


\section{References}

1 Spector A, Ma W, Wang R-R. The aqueous humor is capable of generating and degrading $\mathrm{H}_{2} \mathrm{O}_{2}$. Invest Ophthalmol Vis Sci 1998; 39: 1188-1197.

2 Babizhayev MA, Vishnyakova KS, Yegorov YE. Telomere-dependent senescent phenotype of lens epithelial cells as a biological marker of ageing and cataractogenesis: the role of oxidative stress intensity and specific mechanism of phospholipids hydroperoxide toxicity in lens and aqueous. Fundam Clin Pharmacol 2011; 25: 139-162.

3 Miric D, Kisic B, Zoric L, Dolicanin Z, Mitic R, Miric M. The impact of senile cataract maturity on blood oxidative stress markers and glutathione-dependent antioxidants: relations with lens variables. J Med Biochem 2012; 31: 184-192.

4 Ferreira SM, Lerner FS, Brunyini R, Evelson PA, Llesy SF. Oxidative stress markers in aqueous humor of glaucoma patients. Am J Ophthalmol 2004; 137: 62-69.

5 Sawada H, Fukuchi T, Abe H. Oxidative stress markers in aqueous humor of patients with senile cataract. Curr Eye Res 2009; 34: 36-41.

6 Bagnis A, Izzotti A, Centofanti M, Sacca SC. Aqueous humor oxidative stress proteomic levels in primary open angle glaucoma. Exp Eye Res 2012; 103: 55-62.

7 Ferreira SM, Lerner SF, Brunzini R, Evelson PA, Llesuy SF. Antioxidant status in the aqueous humor of patients with glaucoma associated with exfoliation syndrome. Eye 2009; 23: 1691-1697.

8 Bleau G, Giasson C, Brunette I. Measurement of hydrogen peroxide in biological samples containing high levels of ascorbic acid. Anal Biochem 1998; 263: 13-17.

9 Chajes V, Sattler W, Stultschnig M, Kostner GM. Photometric evaluation of lipid peroxidation products in human plasma and copper oxidized low density lipoproteins: correlation of different oxidation parameters. Atherosclerosis 1996; 121: 193-203.

10 Pamplona R. Membrane phospholipids, lipoxidative damage and molecular integrity: A causal role in ageing and longevity. Biochim Biophys Acta 2008; 1777: 1249-1262.

11 Wu T, Rifai N, Roberts JL, Willett WC, Rimm EB. Stability of measurements of biomarkers of oxidative stress in blood over 36 h. Cancer Epidemiol Biomarkers Prev 2004; 13: 1399-1402.

12 Spector A, Li D, Ma W, Sun F, Pavlidis P. Differential amplification of gene expression in lens cell lines conditioned to survive peroxide stress. Invest Ophthalmol Vis Sci 2002; 43: 3251-3264.

13 Misra HA, Fridovich I. The role of superoxide anion in the autoxidation of epinephrine and a simple assay for superoxide dismutase. J Biol Chem 1972; 247: 3170-3175.

14 Aebi H. Catalase in vitro. Methods Enzymol 1984; 105: 121-126.

15 Shimasaki H. Assay of fluorescent lipid peroxidation products. Methods Enzymol 1994; 233: 338-346.
16 Lowry OH, Rosebrough NJ, Farr LA, Randall RJ. Protein measurement with the Folin phenol reagent. J Biol Chem 1951; 193: 265-275.

17 Borchman D, Yappert MC. Age-related lipid oxidation in human lenses. Invest Ophthalmol Vis Sci 1998; 39: 1053-1058.

18 Wu T, Willett WC, Rifai N, Rimm EB. Plasma fluorescent oxidation products as potential markers of oxidative stress in epidemiological studies. Am J Epidemiol 2007; 166: $552-560$

19 Kim RS, LaBella FS. Comparison of analytical methods for monitoring autoxidation profiles of authentic lipids. J Lipid Res 1987; 28: 1110-1117.

20 Tripathi RC, Millard CB, Tripathi BJ. Protein composition of human aqueous humor: SDS-PAGE analysis of surgical and post-mortem samples. Exp Eye Res 1989; 48: 117-130.

21 Kodama T. Lens crystalline leakage in aqueous humor from human cataractous lenses. Nippon Ganka Gakkai Zasshi 1991; 95: 1065-1070.

22 Behndig A, Svensson B, Marklund SL, Karlsson K. Superoxide dismutase isoenzymes in the human eye. Invest Ophthalmol Vis Sci 1998; 39: 471-475.

23 Goswami S, Sheets NL, Zavadil J, Chauhan BK, Bottinger EP, Reddy VN et al. Spectrum and range of oxidative stress responses of human lens epithelial cells to $\mathrm{H}_{2} \mathrm{O}_{2}$ insult. Invest Ophthalmol Vis Sci 2003; 44: 2084-2093.

24 Rajkumar S, Praveen MR, Gajjar D, Vasavada AR, Alapure B, Patel D et al. Activity of superoxide dismutase isoenzymes in lens epithelial cells derived from different types of age-related cataract. J Cataract Ref Surg 2008; 34: 470-474.

25 De La Paz MA, Epstein DL. Effect of age on superoxide dismutase of human trabecular meshwork. Invest Ophthalmol Vis Sci 1996; 37: 1849-1853.

$26 \mathrm{Xu}$ KY, Kuppusamy P. Dual effects of copper-zinc superoxide dismutase. Biochem Biophys Res Commun 2005 336: 1190-1193.

27 Ramirez DC, Gomez-Mejiba S, Corbett JT, Deterding LJ, Tomer KB, Mason RP. Cu,Zn-superoxide dismutase-driven free radical modifications: copper- and carbonate radical anion-initiated protein radical chemistry. Biochem J 2009; 417: 341-353.

28 Scarf J, Dovrat A. Superoxide dismutase molecules in human lens. Ophthalmic Res 1986; 18: 332-337.

29 Hawse JR, Hejtmancik JF, Huang Q, Sheets NL, Hosack DA Lempicki RA et al. Identification and functional clustering of global gene expression differences between human agerelated cataract and clear lenses. Mol Vis 2003; 9: 515-537.

30 Ho Y-S, Xiong Y, Ma W, Spector A, Ho DS. Mice lacking catalase develop normally but show differential sensitivity to oxidant tissue injury. J Biol Chem 2004; 279: 32804-32812.

31 Kim J, Kim NH, Sohn E, Kim C-S, Kim JS. Methylglyoxal induces cellular damage by increasing argpyrimidine accumulation and oxidative DNA damage in human lens epithelial cells. Biochem Biophys Res Commun 2010; 391: 346-351. 